\title{
The Study of Water Consumption Behavior Under the Societal, Industrial and Environmental Dynamics: A Confirmatory Analysis from the Metropolitan City of Karachi
}

\author{
Muhammad Asif Shamim * $\quad$ Farooq-e-Azam Cheema ${ }^{\dagger} \quad$ Mohammad Omer $\ddagger$ \\ Danish Iqbal Godil $\S$
}

\begin{abstract}
Relevant studies have indicated that water consumption behavior varies with respect to different settings and inhabitants, making the resource subject to scarcity or availability problems. This study aims to identify essential paradigms for routing water preservation practices as the United Nations Sustainable Development Goals (SDG) suggest.Responses were gathered from Karachi (Pakistan) to enable contextualization of past knowledge with its socio-environmental structure. The objective is to gain insights into the mentioned framework to identify the collective behaviors acting within the social groups. A survey based approach was adopted for collecting data, with observed responses amounting to 339 individuals under the simple random sampling technique, followed by inferential modeling to identify the forces present in society with respect to water consumption motives. The results following PLS Structural Equation Modeling showed that the dimensions sharing identities with pricing, quality, vicinity elements, diverse actions and societal criticality all had roles in regulating consumption patterns, some with consumption motives, some without and some with vary degrees according to circumstance ambiguity. Concerned regulations are suggested to focus on motive induction in society for awareness based water conservation. This insight,through framework application,suggests water control implications to the local regulatory institutions, authorities, and managers.
\end{abstract}

Keywords: Karachi, water consumption, water consumption motives, structural equation modeling, Smart PLS.

\section{Introduction}

Among the essential life sustenance resources, fresh water stands within the top necessities nature has to offer. Economic fortification, ecosystem structural development, recreational utility as well as implications covering the cultural element globally require the contribution of fresh water. Compromise of continuous consumption according to the natural

\footnotetext{
${ }^{*}$ Senior Assistant Professor, Cluster Head Economics, Bahria University, Karachi, Pakistan.

Email: asifshamim.bukc@bahria.edu.pk

†Professor, Management Sciences Department, Bahria University, Karachi. Email: dr.cheema@live.com

$\ddagger$ Lecturer, Khadim Ali Shah Bukhari Institute of Technology. Email: umr13489@gmail.com

$\S$ Senior Assistant Professor, Bahria Universty, Karachi, Pakistan. Email: danishiqbal.bukc@bahria.edu.pk
} 
compatibility of fresh water should be observed and controlled to keep the continuum intact which is in line with sustenance as per the concepts described as traditional (World commission on Environment and Development (WCED) 1987). Water, in all its essential status, is a critically demanded resource among various other resources which requires conservation as well as consistent circulation and due to it availability deficit, even while being renewable, is a problem present in both the current and future continuum despite its need significance. Droughts in various areas of Pakistan have caused natural resources in the form of or attributed to water to be present at a delicate platform plaguing its existence. Natural support for water resource sustenance have been adversely fluctuating, including rainfall alongside the consumption variations due to growth in population, water consumption according to per capita increase and development of urban settings.

With a composition of $2.7 \%$ of the worlds accumulated population Pakistan stands among one of the most populated countries in the world at the sixth rank (World Population Prospects, 2009). The recorded increase in the collective population of Pakistan from 1951 to 2017 indicates an increase of 163 Million (i.e. from 34 to 197 Million). The change in percentage attributed to the urban sector was by $22.7 \%$ from 1951 to 2017 (i.e. from $17 \%$ to $39.7 \%$ ) with a per square kilometer density of 220 individuals and 70 million recorded urban individuals. Influence on sectors characterizing domestic, agricultural and industrial segregation based on urbanization on a rapid scale and high rate of growth associated with population led to the water demand increase directly. Relatively thirty-five percent of the domestic facility has not been explored in terms of water consumption. Rankings, presented by Malin Falkenmark and John Waterbury, indicate that Pakistan is near a deficit in water resources in terms of 'Supply Side' criteria. 17000 is the level mentioned, as per the annual record of water resources, according to criteria which when surpassed intermittently or locally, the shortage of renewable fresh water would be present. Scarcity of water becomes apparent at $1000 \mathrm{~m} 2$ per capita on yearly bases or below it (Waterbury J, Gardner-Outlaw T and Englishmen R, 1979). The current or future requirements of fresh renewable water supply are not used as a frame of reference according to the criteria presented by the supply side which is a total representation of a nation's water resources. Management of water resources can be made efficient and effective through a thorough insight of issues in demand and supply of water.

Due to rapid changes in temperature worldwide, population increase and urbanization across the developing world, water scarcity is consistently viewed as a social and environmental problem with serious consequences.

Pakistan is one of the countries which could face serious food and water crises as we progress through the 21st century. Due to extensive struggles for water resources, by domestic and industrial sectors, major cities in Pakistan are already facing intense shortages of water. This has identified groundwater over-extraction, deteriorated water quality, extensive groundwater degradation and floods as direct business risks, where as indirect regulative and name risks arise once water becomes a shared resource among communities and ecosystems. Governmental factors, such as weak regulation and governance are often identified as important demonstrators of these risks (Situation Analysis of the Water Resources of Lahore Report SAWRL, 2005).

Past studies indicate that behaviors pertaining to water utilization stand variable with 
the underlying dynamics of domestic elements as well as industrial practices enabling the investigative contextualization of hydro aspects. Investigative ambitions of the study are to examine the relationship between utilization of hydro based resources and the relative behavior found in society along with attitudes and devices applied in households in urban areas of Pakistan. Methodologies, guiding utilization techniques of hydro based resources, committed to being used for dominating perceptual standard based support, amplify facilities in an exceedingly elaborate method that is both cost-efficient and favorable for the water resources present while still meeting consumer demand (Criticality hierarchy in upcoming hydro utility patterns and innovative procedures and establishment, EUFP7 TRUST project report 2010). A dimension of hydro pattern utility establishment formalization and acceptable norms is present to confirm the security of civilization based hydro sections. Hydro utility pattern establishment, which may be marked because the sensible advancement and application of methods geared towards control demand, square measure utilized globally to help in shifting customers towards continuous water consumption behavior (Deverill P. Sharing, 2010). The WDM approach depends greatly on shoppers to know a way to scale back their hydro utility structure and to use utility foundation for comprehending daily actions associated with it continuously. Mitigation of utility establishment developing allocated utility performance for greater comprehension however hydro resources are employed and the variations among utility patterns allow realization of conservation (Jorgensen, Graymore, \& O'Toole, 2009). It is believed that an understanding of the cultural territory and therefore following the advancement in setting locality circulated living pattern expertise lay with it the critical boundaries of cultural comprehension and importance for accommodating acceptance of continuous innovative standards of inhabitants. If used with relative criticality, WDM may enable even scale back hydro resource and power generation price of inhabitants and circulatory agents of hydro resources, therefore might create and acceptable synergy on waste framework by minimizing peak self administered subjective induction into waste systems, scale back populating hundreds and thereby increase water system and extent the lifetime of aging water framework.

\section{Problem Statement}

Current studies in Pakistan indicate that water as a resource is proportionately subject to contamination making the societal setting vulnerable to disease if not observed and controlled properly (A. Ahmed \& Shafique, 2019). Adding to the issues of water availability, climatic influence on water sources exploits their vulnerability. Other factors included, and this vulnerability becomes a significant hurdle for development at a sustainable level (Shabbir \& Ahmad, 2016). Specific sources of water assigned to serve societal purposes have also fallen subject to these contaminations pointing out that the remainder, usable, portion should be channelized effectively (Rasool et al., 2017). Agro based industrial practices in this context are also contributing to the pollution problem.

The segregation of cost pertaining to the control and distribution of usable water shows that water sources are now undergoing massive treatment procedures to minimize expenditures associated with the recycling of water (Ahmad, Khan, Shafiq, \& Khan, 2019). Affordability in areas such as Karachi is a considerable factor due to the cost allocations 
associated with such treatment activities. Due to the consistent reduction in availability of water a critical problem of managing the remaining water resources and pushing the sustenance efforts to potentially balance them are primary focal points for strategists, along with verifying and spreading public awareness regarding water preservation (W. Ahmed \& Omar, 2017). The knowledgeable judgment of the localities based on the awareness that circulates among them drives their motives for water consumption. If the information is effective their motives serve as conservative drives else the scenario is vice versa which is present at a greater degree as compared to the former. The current management of water resources is poor, considering the overwhelming loss of supply due to lack of effective treatment facilities and methods for wasted water (Amin et al., 2019).

The paper focuses mainly on community attitudes and behaviors related to water consumption in Pakistan, ranging across the analytic sequences placed upon model based behavioral metrics and past hydro utilization investigations. The research questions related to this study are "What are the factors influencing water consumption behavior on people?" and "How much impact these factors are on people's water consumption behavior?". In order to enable the regulatory and institutional bodies to control water consumption habits, the underlying psychometric and experience based drives influential in directing water consumption, if identified and controlled, would significantly prove helpful and beneficial.

\section{Literature Review}

This paper extends the research on water use patterns through an exploring thing of the effect that related to how much money and power people have, attitude-related and behavioral factors may have on water use across city-based areas. It is generally held that reduced water use is fair to reduce the health of the earth and the surrounding conditions stress created by city-based areas, especially in terms of effects on water catchments, wastewater and sewage outputs. Domestic water demand management is to make water available for people without reducing or interfering with the ability to keep around of the system. For helping the planet operation and fair distribution, it is excessively crucial to forecast the water demand by thinking around the social and technical parts of water.

\section{Theoretical Background}

Short run influences on demand of fresh water are closely associated with price. Clarity is not present regarding whether the actual role of marginal price and its awareness is the critical influential element aside from the actual structure of price (e.g, a rise in tariffs placed for block) along with the recurrence of mechanisms defining feedback based on behaviors, the billing patterns of water consumption for instance. The underlying consumption patterns of water are still not clearly defined as driven by direct contemporary requirements or through knowledge about criticality of water and the adverse outcomes associated with its scarcity (considering the motive to conserve water or the integrity of water provision services). The criticality of water pricing may come in active consideration if the vendors providing water supply gain insight into the paradigms commonly associated with water 
consumption stimuli (e.g. restrictions regarding water consumption) in the process of providing directive based decisions (Syme, Shao, Po, \& Campbell, 2004). The effectiveness of strategies involving restricting usage of water or pricing structures may be unclear in terms of their actual influence during times of water scarcity. Still there are queries regarding motivations about water conservation and behaviors that are least apparent in households over time even consumers thought, water is significantly managed by means of restrictions, pricing and the resource related to water resources.

There is requirement of in-depth understanding regarding the water consumption passage as they are intact with urban structure and socioeconomic elements. Center of attention of prior researches was towards the manipulation of income over water utilization. The area where researches have not much focused is how patterns of water utilization vary and how such consumption variations are related with socioeconomic, structural and climate elements (Balling Jr, Gober, \& Jones, 2008). Mostly past researches have focused towards survey at individual basis or the areas which are geographically aggregated (Lee \& Fernando, 2015), contributing restricted value for thoughtful impediment of water utilization at the locality scale. Identifying elements influencing water utilization at neighborhood scale gives spatially targeted policies and resources how water utilization can be managed.

Various kinds of urbanization are related with residential actions on the basis of rental, fitting out and sale of homes, while all of them having the trait of Spanish Mediterranean, since the bubble of property rupture in 2007-08. In between the years 1992-00, 1.2 million habitats were constructed on Spanish Mediterranean coast, alongside 5 million have been constructed in between 2001-11, that is $25 \%$ increment.

Familiarizing the contextual comprehension investigating family varieties and family hydro utility components results in higher visibility if inhabitant consumption sequences; after, additional economical hydro utility and higher statement upcoming for hydro consumption possibilities are apparent. This structures the investigative paramount for necessitating the interruption of domestic hydro utility patterns for enhancing the transparency of studying parts at intervals the family that results in higher understanding of family water consumption patterns and trends. Creating segregated splinters of utility oriented dynamics has been the regulating structural framework composing several investigations. For example, focused on six micro components (e.g. showers, WCs, baths, internal taps, washing machines, and dishwashers). Shaban and Sharma (2007), principally centered per capita relevance within house attribute based micro aspects in critical urban Indian settings. Depicted was that on the average cookery and ingestion was recorded at less than ten $\%$ of water use, with bathing, WC flushing, clothes washing, and utensil washing accounting for much higher water use in households. Since the focus of the survey is principally on bathing/ showering, water utilized in WC, dish-washing, and clothes-washing, here an outline of those appliances is bestowed.

The variables used for the research are, first it is Garden Interest (GI), where garden interest in a household where the like to grow their own foods or plant trees and grow fruits, vegetables and their interest in working in soil and enjoy this activity. Second, Water Quality (WQ), water quality of Karachi's main pipeline of supplying water is poor or good, chemical smell is present in the water, is it safe for drinking or not. Third, Attitude toward Price (AP), the price set by the government or management of supplying the water 
is it at good rate or it is overpricing, in the near future does water will go expensive and rare and accept it as a reality. Fourth, Motives For Conserving Water (WCM), storing the water for later use, less wasting and consumption on water. Fifth, Social Desirability (SD), doing something for the society that will benefit them in the near future and helping to overcome the cause of water shortage and encourage of conserving the water and avoidance of consumption of water. Sixth, Water Consumption (CW), how the people behavior in consumption of water, where they consume the water the most and at what behavior. Seventh, Common Industrialist (CI), the industrialist wastes the water in product or not waste water in manufacturing for benefit in water bill. Eighth, Common Neighbors (CN), neighbor's waste water in cars, waste water in dishes, waste water in plants, repair the leakage in pipes.

\section{Empirical Studies}

A significant body of work has been managed and done before relating to public attitudes to and behaviors relating to water consumption and water restrictions. A summary of research directly linked to the subject of this paper is given below. Overall there is an absence of research managed and done to explore difference in water conservations and attitudes between many places of people live near the mountains, rivers, cities, etc. location.

A. Ahmed and Shafique (2019) extracted evidence of water consumption trends from a metropolitan city in Pakistan pointing out the irregularities and inappropriate water utility patterns. The risk perceptions in the area subject to the investigation were the underlying support for conclusive implications. Findings indicated that awareness levels at a mass, individual and industrial scale address the dynamics of knowledgeable drives as major influencers on consumption habits. Suggestions imply that contingencies drawn under uncertainties quantified in a systematic way may provide a framework capable of structuring water preservation habits realistically.

Ahmad et al. (2019) highlighted the importance of water resources and their negative relationship with natural disasters. Various records of natural disasters were presented as indicators of water endangering events. The outcomes were also associated with the necessity of fortifying the structures of water management practices, which were evidently identified as causes associated with the preservation or loss of water resources. The criticality of innovation and technology became an implicit context of the study for future recommendations.

Leong et al. (2019) compiled the information regarding the essential constituents making the industry functional. Using the knowledgeable basis, the elements driving performance from an environmental perspective were highlighted and measured in contrast with the actual and expected outcomes. Primarily the focal agenda was developing and elaborative framework capable of proposing sustainable solutions for the surrounding industries while utilizing a benchmark based approach. The latest quantitative techniques were utilized to calculate the underlying dynamics in circulation creating the faces of relationships within. Through the application of a thorough knowledgeable approach, a system directing continuous improvement was identified and it validity was gauged. A green framework and lean form of operations took form, constituting a model of enhancing the application of 
industrial operations.

Lindsay and Supski (2017) indicated the criticality of habits relating to water consumption and all other activities comprising water consumption. The study highlighted a significant era of influential proportions which altered the very foundations of water consumption norms by establishing restrictions on the resource. The technique utilized in embodying the study with interpretable information was focus group, enabling the diversities of outcome to be recorded with subjective dynamics. All the change driving dynamics with respect to the observations made for the study enable the identification of changing household trends in the context of water consumption.

Morote, Hernández, and Rico (2016) structured an investigative framework for examining the hydro consumption paradigms in order to contextualize the dynamics of inhabitant perceptions and utility habits from the time frame between 2007 till 2013. The collective observables were sent through analytics to gain insight on the societal complexes surrounding utility patterns oriented by house characteristic based variations. Giving rise to the relative dynamics are the associated scenario induced circumstances establishing physical composite influences. Patters succeeding the analytics presented variation in utility sequences differentiable by financial aspects and inhabitant characteristics.

Yang et al. (2017) studied on domestic water consumption monitoring and behavior intervention by employing the internet of things technology. The water consumption is wirelessly recorded and stored in the central database. Advises are generated for water conservation and tackling the problem of scarcity. This system is used in some other countries also.

Sadr et al. (2016) analyzed domestic water consumption in Jaipur India.The purpose of the study is studying the relationship between water consumption and water use behavior. The methodology used was the questionnaire. 90 households participated in the survey. The results can be used to develop a comprehensive water conservation plan.

Kim Parren and LiliYang (2015) explored the psychometric dimensions present in hydro consumption sequences with the diversity of subjective differentiable attributes and extrinsic induced paradigms. Theoretical underpinnings circulating the behavioral induction dynamics were insightful in presenting a framework based observational conclusion. The association powering co relational foundation was evident by the conclusion derived analytics. Therefore, associations were implicating positive realizations. David Walker et al (2015) Forecasting domestic water consumption from smart meter readings using statistical methods and artificial neural networks. The data is a cross sectional data, it is collected from a case study of iWIDGET case study project in which the data is collected from three location of Europe: Portugal, Greece and United Kingdom. A range of input schemas square measure examined, as well as real meter readings and outline statistics derived from readings. The models resulting from the work used a range of input schemas, contrasting the use of historical input readings with inputs based on summary statistics constructed from those readings. It is found that the models can predict some consumption however struggle to accurately match in case of peak usage.

Yixing Shan et al (2015) Household water consumption: insight from a survey in Greece and Poland.A survey was conducted in Greece and Poland for the household water consumption. The survey was distributed by two universities each from Greece and Poland. 
The result shows that the impact of household size and the income on water consumption was different for Greece and Poland. The association between household ownership and responsiveness to changes in price was inconsistent between respondents from Greece and Poland.

de Miranda Coelho, Gouveia, de Souza, Milfont, and Barros (2016) Emotions towards water consumption: conservation and wastage. The methodology used is a rating scale. Results predict behavioral patterns and emotions intended towards participation in activities towards water conservation.

Fan, Wang, Liu, Yang, and Qin (2014) Public perception of water Consumption and its effects on water conservation behavior. To study the perception that consumers water consumption does not reflect their bills. 776 households in 16 villages were studied in the rural Wei river basin. Questionnaires and 3-day water dairies to collect and compare data. Results show a significant relationship exists between perceived water consumption and actual water consumption.

Sønderlund, Smith, Hutton, and Kapelan (2014) Using smart meters for household water consumption: known and unknowns. The paper has explored and reviewed the evidence base on the effectiveness of consumption feedback in water use and how to tackle demand management and how to quantify end-user demand. The technique used in the paper are smart meters and IHDs. The conclusion of the paper was that the overall possibility of smart meter technology in domestic water is clear but further research is required. The recommendation of this paper is that the role of water pricing needs further analysis as low price of water can intermediate the effect of feedback.

Dolnicar, Hurlimann, and Grün (2012) Water conservation behavior in Australia. The paper focuses on both supply side and demand side approaches. The main aim is to reveal the main drivers from a comprehensive pool of hypothesized factors. 3094 Australians took part in the study. The methodology used was a multivariate linear regression analysis and decision trees.

Zivin, Neidell, and Schlenker (2011) Water quality violations and avoidance behavior: evidence from bottled water consumption. The data used in this paper is from the national grocery chain matched with water quality violations, obtained historical information on all violations that occurred in the USA from 2001-2005. Dependent variable weekly sales of the water bottle and independent variable water store district and vector violation. Find a rise in drinking water sales of twenty-two percent from violations thanks to micro-organisms and seventeen percent violations thank to components and chemicals. The calculation yield prices of shunning behavior at approximately sixty million dollars for all governmental violations in 2005, that possible match a big statement of the entire temperament to pay to erase violations.

Chang, Parandvash, and Shandas (2010) Spatial variations of single-family residential water consumption in Portland, Oregon. To evaluate the act of city-based advancement arrangement on the water. In this paper the researcher used a GLS and statistical models of OLS regression model to analyze single-family where there are lots of homes, water used inside the Portland, Oregon, urban house result shows that urban water consumption per social unit at the demography block cluster is best interpreted by average building size and it is followed by the building density and building age with low water consumption ar- 
eas gathering together and commonly placed in high density and older neighborhoods.The result made by OLS regression model predicts that seventy-one percent of the water consumption in all census and it shows a strong relationship between the consumption and building size. The relation between consumption and density shows significant but negative in relation and also negative relation between consumption and building age.

Jorgensen et al. (2009) Household water use behavior: an integrated model. The study was conducted to develop effective water management programs. Due to climate change increase in population and drought. The study says the households won't conserve water when they feel others are not doing so and if they do not trust their authority of water management.

Randolph and Troy (2008) Attitudes to conservation and water consumption.This paper examines the approach of household to their water consumption and search a way to find to reduce the water demand. Data used for the research was collected through a random allocation of telephone survey around more than two thousand addresses in a stratified sample of 140 census collector?s district. The result shows that the people are aware that there is an important issue of water conservation in the area and people are willing to effort to overcome this issue.

Balling Jr et al. (2008) Sensitivity of residential water consumption to variations in climate: an intra urban analysis of Phoenix, Arizona. This paper explores spatial variations in the sensitivity of residential water consumption with atmospheric conditions. A census was occurred for data collection. The result shows that the consumption of water in Phoenix had a positive relation with the variation of climate and greater sensitivity of atmospheric condition had occurred.

Mu, Whittington, and Briscoe (1990) Modelling village water demand behavior: A discrete choice approach. His model is calculable with information collected by in-depth personal interviews with sixty-nine households in Ukunda, Kenya, a small town south of Mombasa. The result counsel that households' supply alternative choices area unit influenced by the time it takes to gather water from totally different sources, the price of water, and the number of women in a household. Household financial gain, however, did not have a statistically significant effect. Essentially constant information was accustomed to estimate a conventional water demand model that tries to clarify the amount of water demanded by home as a operate of collection time, income, and other socioeconomic variables. The result of the distinct alternative and ancient water usage model?s area unit compared during this paper.

\section{Methodology}

\section{Instrument and Measures}

Considering the natural and attributive similarities of the subject analyzed in this study (Mu et al., 1990; Fan et al., 2014; Morote et al., 2016) relevant techniques were used to gather measurable evidence of cause and effect among the driving forces for water consumption and the actual consumption as utilized in previous respective researches (CorralVerdugo, Frias-Armenta, Pérez-Urias, Orduña-Cabrera, \& Espinoza-Gallego, 2002). Ex- 
ogenous constructs extracted from the mentioned studies included Common Neighbors, Social Desirability, Common Industrialists, Attitude towards Price, Water quality and Garden Interest. The analysis incorporated a construct measuring the motives for consuming water at a mediating variable for enhancing the statistical strength of the model while adding an extra dimension for exploration. The endogenous construct adopted for the study was water consumption. Sample observations were recorded on survey instruments including 41 close ended adopted items composed of 5 point likert scales each. From point 1 "Strongly Disagree" to point 5 "Strongly agree".

Experimental research algorithms along with correlation based analytics are utilized in this study to establish the causal foundations of the statistical model.

\section{Sample and Data Collection}

House hold inhabitants according to the research requirements were chosen at random with the instrument itself identifying the clusters within the sample of effective respondents.

\begin{tabular}{|c|c|c|c|}
\hline Description & Sample Size $=339$ ) & Frequency & Percentage \\
\hline \multirow{2}{*}{ Gender } & Male & 165 & 48.7 \\
\hline & Female & 174 & 51.3 \\
\hline \multirow[t]{3}{*}{ Age Group } & $22-30$ & 197 & 58.1 \\
\hline & $30-40$ & 73 & 21.5 \\
\hline & $>40$ & 69 & 20.4 \\
\hline \multirow[t]{4}{*}{ Education } & Undergraduate & 149 & 44 \\
\hline & Graduate & 97 & 28.6 \\
\hline & Masters & 85 & 25.1 \\
\hline & Phd & 8 & 2.4 \\
\hline No of Years & $<2$ & 32 & 9.4 \\
\hline Lived in & 02-Apr & 36 & 10.6 \\
\hline \multirow[t]{4}{*}{ Karachi } & 05-Sep & 30 & 8.8 \\
\hline & Oct-14 & 41 & 12.1 \\
\hline & $15-20$ & 59 & 17.4 \\
\hline & $>20$ & 141 & 41.6 \\
\hline \multirow[t]{6}{*}{ District } & Central & 80 & 23.6 \\
\hline & East & 70 & 20.6 \\
\hline & South & 36 & 10.6 \\
\hline & West & 52 & 15.3 \\
\hline & Korangi & 45 & 13.3 \\
\hline & Malir & 56 & 16.5 \\
\hline \multirow[t]{6}{*}{ Income Group } & $<20000$ & 69 & 20.4 \\
\hline & $20000-40000$ & 67 & 19.8 \\
\hline & $40000-60000$ & 57 & 16.8 \\
\hline & $60000-80000$ & 36 & 10.6 \\
\hline & $80000-100000$ & 65 & 19.2 \\
\hline & $>100000$ & 45 & 13.3 \\
\hline \multirow[t]{4}{*}{ Family Size } & 01-Apr & 107 & 31.6 \\
\hline & 05-Aug & 129 & 38.1 \\
\hline & 09-Nov & 52 & 15.3 \\
\hline & $>12$ & 51 & 15 \\
\hline
\end{tabular}

Source: Authors' Estimation

Utilizing simple random sampling all respondents equally held the probability of selection (Zhu, Sarkis, \& Lai, 2012; Gimenez, van der Vaart, \& van Donk, 2012). The sample 
of above 200 respondents in this study stands in the comfort zone according to previous studies. Questionnaires were distributed to a total of 500 individuals of which 347 (i.e. a $69.4 \%$ response) were returned for data imputation. 339 responses were found usable after gaps in the filling patterns.

7 categorical segregation were considered for classifying the demographic profile for this study in order to characterized the sample obtained (Table 1).

\section{Common Method Variance}

The survey instrument, due to its combination of different constructs, poses as a source of common variance bias (CVB) within the data collected using it (W. Ahmed \& Omar, 2017). If there is an abundant covariance anomaly existent in a single factor composed of all constructs extracted through exploratory factor analysis then the issue of common variance bias is a major consideration. Common variance bias in this data set was analyzed through a multi approach method. The single factor approach presented by Harman in 1967 was used as a primary measure for Common Variance Bias through SPSS. The analysis under EFA using Eigen's value greater than 1 and no rotation showed that $56.10 \%$ of the variance was being explained by the 7 factors which emerged and only $33.833 \%$ of the variance was being explained the first factor indicating that the problem of Common Variance Bias did not exist. Another indication of the method bias presence is shown by values greater than 0.9 in inter-construct correlations (Ali, Kim and Ryu, 2016). 0.671 is the highest value observed in the results of inter-construct correlations indicating that the method bias in this study is a major concern.

\section{Variable Descriptions}

\section{Common Neighbors}

The terminology refers to the commonalities in motives of neighboring inhabitants. Their motives, regarding the consumption and preservation patterns of water may be similar or variable compared to the motives of their respective surrounding inhabitants (CorralVerdugo et al., 2002). Regardless of motives, the actual manifested utility of common neighbors without their strategic implications is a dynamic of water consumption, whether wasteful of conservative (Jorgensen et al., 2009).

\section{Social Desirability}

A measure of acceptable society based characteristics was depicted by a number of habits observed in the surrounding inhabitants of the respondents with respect to water utilization patterns. These took the face of miscellaneous concerns presented by the users regarding the issues with water consumption (Syme et al., 2004). The associated linkage with entities, other than social inhabitants, points towards their focus on corporate practices with respect to the importance they place on social welfare (Costanigro, Deselnicu, \& McFadden, 2016). 


\section{Common Industrialists}

From a utility and effectiveness perspective in the industrial operational structures, the actual productive orientation of all entities in the network is the prevalent outcome giving focus to the surrounding inhabitants regarding wasteful as well as recycling practices considerable and acceptable in the society. The dynamics with which industrialists operate are the subjective influences giving the directive frameworks for running the productive functions within these industries to the point that they determine the societal acceptance of industries with respect to water consumption, wastage and conservation (Leong et al., 2019).

\section{Attitude towards Price}

The perceptive ambiguities regarding pricing attribution to water are numerous and abundant in variances. It extends to influencing individuals and profit-based entities alike into considering price as either an irrelevant connection to water consumption or completely negligible. The nature of water is considered by most as necessity oriented rather than market function oriented (Randolph \& Troy, 2008). Sustenance and societal differentiation are considerable binders of price with water consumption. Guided by environmental fortification requirements, the attitude towards price is driven towards a questionable status as to whether price attribution according to scarcity or demand is necessary or should necessity remain the primary factor mitigating the association of price with water consumption (Garrone, Grilli, \& Marzano, 2019).

\section{Water Quality}

The shared opinion in past studies points out that the quality of water provided by the distribution network of the resource with respect to type of utility and the quality demanded by each type is determined through examination of quality practices and measured based on the violations of quality against these practices. Focus on water quality is primarily considered under the utility of drinking, pointing out that preliminary knowledge showing criticality to quality creates a substitution effect with respect to the dynamics of water offerings (Zivin et al., 2011). Surrounding as well as internally prevalent contamination in the water compositions and eco systems drive the resource's availability indices causing concern in the attitudes of locality inhabitants and influencing their water assessment criteria. The scarcity created through these irregularities creates the necessity of regulating water flow in synchronization with the respective environmental systems (Liu, Liu, \& Yang, 2016).

\section{Garden Interest}

Composite elements forming the dimensions associated with garden interest primarily comprised recreational activity types commonly undertaken for personal fulfillment, regular comfort and environmental aesthetics. The socio-demographic comparative provides indicative evidence in contrast with former mentioned behavioral observations currently com- 
munity prevalent following a loop of subsequences commoners use to define their life styles and health oriented motivations (Syme et al., 2004). Utility differentiation has compelled water consumers to diversify their water sourcing tactics. Gardening itself requiring a great degree of flexibility in terms of availability timeliness and quantity dynamics has pushed the need for creating alternative strategies for water collection (Lindsay \& Supski, 2017) implying the enhancement of practical observation among inhabitants.

\section{Motives of Water Consumption}

Constituents of pro-environmental and pro-ecological foundations structuring research backgrounds in identifying water consumption pattern within societal compositions depict the varying degrees of motivations given shape through exogenous influences. Conservation becomes a critical part among the varying motives as it creates an influence in the water consumption loop present in localities (Corral-Verdugo et al., 2002). Combined with intrinsic influence, based on ethical considerations, to conserve the resource helps in further filtering the aspects of criticality regarding actual effective motives driving consumption (de Miranda Coelho et al., 2016). Despite the nature of water as a resource, necessity is a mere fraction of the driving forces influencing consumption habits.

\section{Actual Water Consumption}

Under the considerable influences which structure the perception for consumption patterns, the real time consumption is a composition of contemporary requirements ranging from daily necessities and habitual activities. The level of synchronization they have with the underlying exogenous influences has been questioned and partially observed in past studies (Randolph \& Troy, 2008; Leong et al., 2019). Nevertheless, influential role is a critical boundary composed of the various realistic socio-environmental dynamics corresponding with actual water consumption.

\section{Data Analysis}

The effects of societal paradigm based constructs including common neighbors (CN), Social desirability (SD), Common Industrialists (CI), Attitude towards price (AP), Water Quality (WQ), and Garden Interest (GI) on The motives of water consumption (WCM) followed by actual Water Consumption (WC) were analyzed under the study objectives of this research.

The validation of the statistical framework proposed for this study was conducted as a major requirement for conducting any form of quantitative research in the form of composite data measurement, instrument application; construct correlations, fitness of the final research the model etc. (Hair, Ringle, \& Sarstedt, 2011). Data was put through pilot testing to remove the raw unusable observations and rectify the irregularities using SPSS. Partial Least Square algorithm in smart PLS followed by bootstrapping was applied on the rectified data set to validate and run the model fitness assessment on the proposed model. 


\section{The Measurement of Outer Model}

Examination of the hypotheses proposed, the inner model, was conducted after validating and establishing the reliability of the outer model using SmartPLS 3.2.4. A sequence of model validations in the order; content, convergent and discriminant validity was utilized as the validation criteria.

\section{Content Validity}

Confirmatory factor analysis in the sequence of content validity is the manifestation of construct loadings in each factor known as cross loadings. All the constructs are required to be strongly loaded in each relevant factor (Chin, 1998; Hair, Ringle, \& Sarstedt, 2013).

\begin{tabular}{|c|c|c|c|c|c|c|c|c|c|}
\hline Constructs & Items & AP & CI & $\mathrm{CN}$ & GI & WCM & SD & WC & WQ \\
\hline \multirow[t]{4}{*}{$\mathrm{AP}$} & AP_2 & 0.750 & & & & & & & \\
\hline & AP_3 & 0.795 & & & & & & & \\
\hline & AP_4 & 0.805 & & & & & & & \\
\hline & AP_5 & 0.753 & & & & & & & \\
\hline \multirow[t]{3}{*}{$\mathrm{CI}$} & CI_2 & & 0.830 & & & & & & \\
\hline & CI_3 & & 0.842 & & & & & & \\
\hline & CI_6 & & 0.776 & & & & & & \\
\hline \multirow[t]{4}{*}{$\mathrm{CN}$} & CN_2 & & & 0.752 & & & & & \\
\hline & CN_3 & & & 0.770 & & & & & \\
\hline & CN_4 & & & 0.756 & & & & & \\
\hline & CN_5 & & & 0.736 & & & & & \\
\hline \multirow[t]{4}{*}{ CW } & CW_1 & & & & & & & 0.717 & \\
\hline & CW_2 & & & & & & & 0.847 & \\
\hline & CW_3 & & & & & & & 0.875 & \\
\hline & CW_4 & & & & & & & 0.830 & \\
\hline \multirow[t]{4}{*}{ GI } & GI_2 & & & & 0.758 & & & & \\
\hline & GI_3 & & & & 0.717 & & & & \\
\hline & GI_4 & & & & 0.747 & & & & \\
\hline & GI_5 & & & & 0.750 & & & & \\
\hline \multirow[t]{5}{*}{$\mathrm{SD}$} & SD_1 & & & & & & 0.813 & & \\
\hline & SD_2 & & & & & & 0.812 & & \\
\hline & SD_3 & & & & & & 0.832 & & \\
\hline & SD_4 & & & & & & 0.765 & & \\
\hline & SD_5 & & & & & & 0.753 & & \\
\hline \multirow[t]{4}{*}{ WCM } & WCM_1 & & & & & 0.748 & & & \\
\hline & WCM_2 & & & & & 0.792 & & & \\
\hline & WCM_3 & & & & & 0.802 & & & \\
\hline & WCM_4 & & & & & 0.805 & & & \\
\hline \multirow[t]{5}{*}{ WQ } & WQ_1 & & & & & & & & 0.729 \\
\hline & WQ_2 & & & & & & & & 0.829 \\
\hline & WQ_3 & & & & & & & & 0.833 \\
\hline & WQ_4 & & & & & & & & 0.800 \\
\hline & WQ_5 & & & & & & & & 0.703 \\
\hline
\end{tabular}

Items loading onto their relevant constructs above a specific value (0.7) are kept in the analysis. The ones which are below this value or not loading onto the relevant factor are removed from the analysis to improve the validity of the outer model. The concept related to the construct is being represented by the loadings over 0.7 with significant $\mathrm{P}$ values as 
shown in Tables 2 and 3 .

\begin{tabular}{|c|c|c|c|c|c|}
\hline Constructs & Items & Loadings & $\begin{array}{c}\text { Standard } \\
\text { Error }\end{array}$ & T Statistics & P Values \\
\hline \multirow[t]{4}{*}{$\mathrm{AP}$} & AP_2 & 0.750 & 0.030 & 24.837 & 0.000 \\
\hline & AP_3 & 0.795 & 0.023 & 34.397 & 0.000 \\
\hline & $\mathrm{AP}_{-} 4$ & 0.805 & 0.023 & 35.107 & 0.000 \\
\hline & AP_5 & 0.753 & 0.035 & 21.566 & 0.000 \\
\hline \multirow[t]{3}{*}{ CI } & CI_2 & 0.830 & 0.022 & 37.609 & 0.000 \\
\hline & CI_3 & 0.842 & 0.020 & 42.401 & 0.000 \\
\hline & CI_6 & 0.776 & 0.031 & 25.124 & 0.000 \\
\hline \multirow[t]{4}{*}{$\mathrm{CN}$} & CN_2 & 0.752 & 0.028 & 27.014 & 0.000 \\
\hline & CN_3 & 0.770 & 0.033 & 23.681 & 0.000 \\
\hline & CN_4 & 0.756 & 0.031 & 24.606 & 0.000 \\
\hline & CN_5 & 0.736 & 0.033 & 22.286 & 0.000 \\
\hline \multirow[t]{4}{*}{$\mathrm{CW}$} & CW_1 & 0.717 & 0.040 & 18.134 & 0.000 \\
\hline & CW_2 & 0.847 & 0.020 & 42.101 & 0.000 \\
\hline & CW_3 & 0.875 & 0.015 & 56.788 & 0.000 \\
\hline & CW_4 & 0.830 & 0.021 & 40.287 & 0.000 \\
\hline \multirow[t]{4}{*}{ GI } & GI_2 & 0.758 & 0.030 & 25.194 & 0.000 \\
\hline & GI_3 & 0.717 & 0.032 & 22.135 & 0.000 \\
\hline & GI_4 & 0.747 & 0.034 & 21.929 & 0.000 \\
\hline & GI_5 & 0.750 & 0.031 & 23.877 & 0.000 \\
\hline \multirow[t]{5}{*}{ SD } & SD_1 & 0.813 & 0.025 & 32.108 & 0.000 \\
\hline & SD_2 & 0.812 & 0.021 & 39.335 & 0.000 \\
\hline & SD_3 & 0.832 & 0.020 & 42.276 & 0.000 \\
\hline & SD_4 & 0.765 & 0.026 & 29.898 & 0.000 \\
\hline & SD_5 & 0.753 & 0.027 & 28.108 & 0.000 \\
\hline \multirow[t]{4}{*}{ WCM } & WCM_1 & 0.748 & 0.030 & 25.149 & 0.000 \\
\hline & WCM_2 & 0.792 & 0.023 & 34.121 & 0.000 \\
\hline & WCM_3 & 0.802 & 0.024 & 32.997 & 0.000 \\
\hline & WCM_4 & 0.805 & 0.024 & 33.555 & 0.000 \\
\hline \multirow[t]{5}{*}{ WQ } & WQ_1 & 0.729 & 0.036 & 20.136 & 0.000 \\
\hline & WQ_2 & 0.829 & 0.022 & 38.259 & 0.000 \\
\hline & WQ_3 & 0.833 & 0.020 & 40.916 & 0.000 \\
\hline & WQ_4 & 0.800 & 0.026 & 31.293 & 0.000 \\
\hline & WQ_5 & 0.703 & 0.033 & 21.395 & 0.000 \\
\hline
\end{tabular}

Source: Authors' Estimation

\section{Convergent Validity}

When a collection of relative items validate a construct by converging onto a single concept it is a confirmation of convergent validity (Hair et al., 2013). Convergent validity is a composition of three measures including 0.7 or above factor loadings and composite reliability for each construct and 0.5 and above Average Variance Extracted (AVE) (Fornell \& Larcker, 1981). All Validations are confirmed in Table 4.

\section{Discriminant Validity}

The validation observed through the capacity of a collection of items discriminating them from items of other constructs is known as discriminant validity (W. Ahmed \& Omar, 2017; Mehmood \& Najmi, 2017). 
Table 4

Convergent Validity

\begin{tabular}{|c|c|c|c|c|}
\hline Constructs & Items & Loadings & CR & AVE \\
\hline \multirow[t]{4}{*}{$\mathrm{AP}$} & AP_2 & 0.750 & 0.858 & 0.602 \\
\hline & AP_3 & 0.795 & & \\
\hline & AP_4 & 0.805 & & \\
\hline & AP_5 & 0.753 & & \\
\hline \multirow{3}{*}{ CI } & CI_2 & 0.830 & 0.857 & 0.667 \\
\hline & CI_3 & 0.842 & & \\
\hline & CI_6 & 0.776 & & \\
\hline \multirow[t]{4}{*}{$\mathrm{CN}$} & CN_2 & 0.752 & 0.840 & 0.568 \\
\hline & CN_3 & 0.770 & & \\
\hline & CN_4 & 0.756 & & \\
\hline & CN_5 & 0.736 & & \\
\hline \multirow[t]{4}{*}{$\mathrm{CW}$} & CW_1 & 0.717 & 0.891 & 0.672 \\
\hline & CW_2 & 0.847 & & \\
\hline & CW_3 & 0.875 & & \\
\hline & CW_4 & 0.830 & & \\
\hline \multirow[t]{4}{*}{ GI } & GI_2 & 0.758 & 0.832 & 0.552 \\
\hline & GI_3 & 0.717 & & \\
\hline & GI_4 & 0.747 & & \\
\hline & GI_5 & 0.750 & & \\
\hline \multirow[t]{5}{*}{$\mathrm{SD}$} & SD_1 & 0.813 & 0.896 & 0.633 \\
\hline & SD_2 & 0.812 & & \\
\hline & SD_3 & 0.832 & & \\
\hline & SD_4 & 0.765 & & \\
\hline & SD_5 & 0.753 & & \\
\hline \multirow[t]{4}{*}{ WCM } & WCM_1 & 0.748 & 0.867 & 0.619 \\
\hline & WCM_2 & 0.792 & & \\
\hline & WCM_3 & 0.802 & & \\
\hline & WCM_4 & 0.805 & & \\
\hline \multirow[t]{5}{*}{ WQ } & WQ_1 & 0.729 & 0.886 & 0.609 \\
\hline & WQ_2 & 0.829 & & \\
\hline & WQ_3 & 0.833 & & \\
\hline & WQ_4 & 0.800 & & \\
\hline & WQ_5 & 0.703 & & \\
\hline
\end{tabular}

Source: Authors' Estimation

Table 5

Correlations of Discriminant Validity

\begin{tabular}{lcccccccc}
\hline Constructs & AP & CI & CN & GI & WCM & SD & CW & WQ \\
\hline AP & 0.776 & & & & & & & \\
CI & 0.359 & 0.817 & & & & & & \\
CN & 0.334 & 0.537 & 0.754 & & & & & \\
GI & 0.613 & 0.444 & 0.442 & 0.743 & & & & \\
WCM & 0.563 & 0.592 & 0.596 & 0.627 & 0.787 & & & \\
SD & 0.413 & 0.592 & 0.615 & 0.448 & 0.665 & 0.795 & & \\
CW & 0.412 & 0.559 & 0.618 & 0.458 & 0.671 & 0.611 & 0.820 & \\
WQ & 0.371 & 0.490 & 0.500 & 0.438 & 0.604 & 0.594 & 0.579 & 0.780 \\
\hline
\end{tabular}

Source: Authors' Estimation

The three methods present for evaluating discriminant validity are as follows; a difference of 0.1 or greater should be present between the loadings on the other constructs not relevant to the construct and the loadings of the items relative to the constructs. The suggestion put forth by Fornell and Larcker (1981) directs that the square roots of Average Variance Extracted found in the diagonal in Table 5 should be greater than the values of correlations of other constructs found in the other columns which is the case as shown in the results. 
The confirmation of discriminant validity is positive, therefore. And finally the heterotraitmonotrait ratio (HTMT) should be composed of value less than 0.85 in its matrix for discriminant validity to be present. Positive validations are shown in Tables $5 \& 6$.

\begin{tabular}{|c|c|c|c|c|c|c|c|c|}
\hline Constructs & AP & CI & $\mathrm{CN}$ & GI & WCM & SD & CW & WQ \\
\hline \multicolumn{9}{|l|}{$\mathrm{AP}$} \\
\hline CI & 0.466 & & & & & & & \\
\hline $\mathrm{CN}$ & 0.436 & 0.713 & & & & & & \\
\hline GI & 0.806 & 0.600 & 0.596 & & & & & \\
\hline WCM & 0.708 & 0.764 & 0.772 & 0.816 & & & & \\
\hline SD & 0.506 & 0.737 & 0.768 & 0.562 & 0.806 & & & \\
\hline CW & 0.506 & 0.704 & 0.777 & 0.578 & 0.821 & 0.718 & & \\
\hline WQ & 0.456 & 0.616 & 0.632 & 0.553 & 0.740 & 0.701 & 0.689 & \\
\hline
\end{tabular}

\section{The Structural Model and Test of Hypothesis}

Following the procedures of validation the hypotheses proposed in the study were test through partial least square structural equation modeling. The potential of PLS SEM was a critical reason for selecting to carry out this analysis as it was greatly utilizable for structural models of a reflective nature. Its estimation fortification as compared to covariance based techniques was greater adding tore sons for utilizing this technique (Hair et al., 2011; Hair, Sarstedt, Ringle, \& Mena, 2012). Bootstrapping was done at 5000 samples to extract the significance of inter-construct correlations. The direct effects of the exogenous constructs on the mediator followed by the final endogenous construct are shown (Figures $1 \& 2$ ). The Mediation effects are shown with paths connecting all the exogenous constructs with the endogenous constructs as well as separately passing thorough the mediator (Figures $3 \& 4$ ).

\section{Predictive Relevance of the Model}

The accumulated variance explained is represented by the R-Squared value in terms of all constructs. The strength factor of the mentioned explanatory value is segregated as 0.26 , 0.13 and 0.02 for strong, mild and weak respectively. The relative connections if existent in the model can be identified by a measure known as Q-Squared. Values showing presence of predictive power are observed as greater than zero.

Table 7

Predictive Power of the construct

\begin{tabular}{llll}
\hline & $R^{2}$ & Adjusted $R^{2}$ & $Q^{2}$ \\
\hline WCM & 0.655 & 0.649 & 0.396 \\
CW & 0.451 & 0.449 & 0.300 \\
(With Mediation) & & & \\
WCM & 0.655 & 0.649 & 0.397 \\
CW & 0.568 & 0.559 & 0.376 \\
\hline \multicolumn{4}{l}{ Source: Authors' Estimation }
\end{tabular}


Minor differences between the R-Squared and Q-Squared are indicators high predictive capacities (Hair et al., 2011; Hair Jr, Sarstedt, Hopkins, \& Kuppelwieser, 2014). Generated results indicate that the predictive capacities of the exogenous constructs ('Motives of water consumption' influencers) is strong (i.e. over 0.26).

The measure of goodness of fit (GoF) is another validation criterion in Partial Least Square (SEM). The guidelines suggested recently, although, indicate that GoF is not a suitable measure for every research model utilizing partial least square (Hair Jr, Hult, Ringle, \& Sarstedt, 2016). The calculation of this test for model fitness is done using the Average Variance Extracted and indicators showing predictive capacities (R-Squared).

The values segregating the thresholds for strong, mild and weak model fitness are 0.36, 0.25 and 0.1 respectively. The final values are 0.583 and 0.609 indicating a strong model.

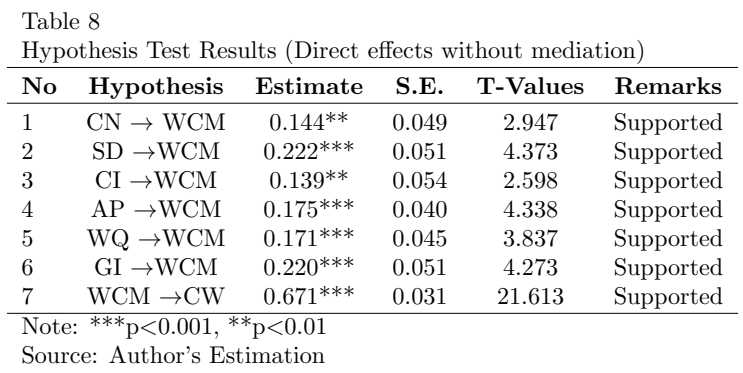

The direction and size of effects of exogenous constructs on endogenous constructs are indicated by estimates (Beta Coefficients). The direction may be positive or negative and shifts according to the weight of the estimate with every other variable remaining constant. 'Common Neighbors', 'Social Desirability', 'Common Industrialists', 'Attitude towards price', 'Water Quality' and 'Garden Interest' have estimates as follows; 0.144, 0.222, $0.139,0.175,0.171$ and 0.220 respectively with P-Values less than 0.001 except for Common Neighbors and Common Industrialists which have P-Values less than 0.01. The effects size of 'Motives of Water consumption' of 'Water Consumption' is 0.671 with a p-value of less than 0.001. All the research hypothesis suggesting direct effects of the exogenous on motives followed by the effects of motives on consumption were found supported after the analysis.

\begin{tabular}{|c|c|c|c|c|c|}
\hline No & Hypothesis & Estimate & S.E. & T-Values & Remarks \\
\hline 1 & $\mathrm{CN} \rightarrow \mathrm{CW}$ & $0.238^{* * *}$ & 0.051 & 4.613 & Supported \\
\hline 2 & $\mathrm{SD} \rightarrow \mathrm{CW}$ & $0.104(\mathrm{~ns})$ & 0.060 & 1.734 & Not Supported \\
\hline 3 & $\mathrm{CI} \rightarrow \mathrm{CW}$ & $0.117^{*}$ & 0.050 & 2.339 & Supported \\
\hline 4 & $\mathrm{AP} \rightarrow \mathrm{CW}$ & $0.039(\mathrm{~ns})$ & 0.044 & 0.898 & Not Supported \\
\hline 5 & $\mathrm{WQ} \rightarrow \mathrm{CW}$ & $0.166^{* *}$ & 0.053 & 3.155 & Supported \\
\hline 6 & $\mathrm{GI} \rightarrow \mathrm{CW}$ & $-0.013(\mathrm{~ns})$ & 0.051 & 0.255 & Not Supported \\
\hline 7 & $\mathrm{WCM} \rightarrow \mathrm{CW}$ & $0.277^{* * *}$ & 0.068 & 4.106 & Supported \\
\hline
\end{tabular}

The mediation effects are measured with the path of the main exogenous variables 
connected directly with the endogenous variables and at the same time also passing through the mediator (Costa \& Monteiro, 2016). The direct effects of the model with the mediation path incorporated are 0.238, 0.104, 0.117, 0.039, 0.166 and -0.013 for 'Common Neighbors', 'Social Desirability', 'Common Industrialists', 'Attitude towards price', 'Water Quality' and 'Garden Interest' respectively with 'common neighbors' and 'water quality' showing significant effect on 'Water consumption' having P-Values less than 0.01 and 'Common Industrialists' having P-Values less than 0.05. 'Social Desirability', 'Attitude towards price' and 'Garden Interest' were identified as insignificant indicators of 'Water Consumption'. 'Motives for Water Consumption' itself with the accompanying other indicators was found to have an effect size of 0.277 with a significant p-Value less than 0.001 (Table-9).

\begin{tabular}{|c|c|c|c|c|c|}
\hline No & Hypothesis & Estimate & S.E. & T-Values & Remarks \\
\hline 1 & $\mathrm{CN} \rightarrow \mathrm{WCM} \rightarrow \mathrm{CW}$ & $0.040^{* *}$ & 0.018 & 2.216 & Supported \\
\hline 2 & $\mathrm{SD} \rightarrow \mathrm{WCM} \rightarrow \mathrm{CW}$ & $0.062^{* *}$ & 0.021 & 2.948 & Supported \\
\hline 3 & $\mathrm{CI} \rightarrow \mathrm{WCM} \rightarrow \mathrm{CW}$ & $0.038^{* *}$ & 0.017 & 2.243 & Supported \\
\hline 4 & $\mathrm{AP} \rightarrow \mathrm{WCM} \rightarrow \mathrm{CW}$ & $0.048^{* *}$ & 0.017 & 2.837 & Supported \\
\hline 5 & $\mathrm{WQ} \rightarrow \mathrm{WCM} \rightarrow \mathrm{CW}$ & $0.047^{* *}$ & 0.016 & 2.971 & Supported \\
\hline 6 & $\mathrm{GI} \rightarrow \mathrm{WCM} \rightarrow \mathrm{CW}$ & $0.061^{* *}$ & 0.021 & 2.869 & Supported \\
\hline
\end{tabular}

The indirect effects show the actual contribution of the mediator variable(s) in the model with two types of effects i.e. full mediation and partial mediation. Partial mediation is indicated by significant effects of the exogenous variables on the endogenous both directly and through the mediator variable. Full mediation indicates that the direct effects of the exogenous variable(s) on the endogenous variable(s) are insignificant while the stand significant with the incorporation of a mediator. The indirect effects of the model with the mediation path incorporated are $0.040,0.062,0.038,0.048,0.047$ and 0.061 for 'Common Neighbors', 'Social Desirability', 'Common Industrialists', 'Attitude towards price', 'Water Quality' and 'Garden Interest' respectively with significant P-Values less than 0.01 (Table -10). This indicates partial mediation for 'Common Neighbors', 'Common Industrialists', 'Water Quality' and full mediation for 'Social Desirability', 'Attitude towards price' and 'Garden Interest' with 'Motives for Water Consumption' incorporated as a mediator between them and the variable 'Water Consumption'.

\section{Conclusion}

The indication of changes in water consumption due to the incorporation of 'Water consumption Motives' was the core focus of this study. The primary independent constructs were chosen from past studies because they were indicating a drive for water consumption but in the context of the observations made for this study the framework of investigation was different as it represented a unique direction for incorporating another dimension contributing to water consumption. The results preliminary to the final analysis with the mediation effect indicated that all the exogenous dimensions had a positive significant ef- 
fect on Motives to consume water which points out that all the independent variables were suited to measuring the influences on motives. Industrial practices, habits of neighbors, the price associated with water, the societal requirements of water, the requirement for cottage irrigation and individual production of agriculture along with the quality of water itself were found associable with the motives for consuming water. The actual consumption of water was also found as directly associable with the actual indictor of water consumption.

The analysis forming the actual basis of this study indicated that the case was different if the motives of water consumption were used as a mediating influence on the relationships between the exogenous dimensions and the endogenous construct. Overall outcome of the statistical analysis indicated that half of the independent dimensions were not directly correlated with water consumption and required the mediation of water consumption motives to manifest a relationship with consumption practices. The dimensions which fully depended upon mediation included Garden Interest, Attitude towards price and Social Desirability. Since the underlying exploratory platform of garden interest includes perceptive attributes like self motivation for gardening or focusing on a cottage industry like use for water in gardening to increase ground consumable produce while gardening as generally observed in society has variable scale and motivation, it can be contextualized that people with even the smallest garden may or may not give it the proper attention in terms of water utilization owing to their living patterns. Therefore it is imperative that there should be proper motives to fuel the consumption of water for gardening consistently. Another observable generalization in society is the association of water usage and the perception people hold in terms of water conservation i.e. it can be justified that people may be consuming water at variable quantities while not giving much thought to their societal perceptions, they may waste it at will or conserve at will which implies that motives, when present, can actually channelize the relationship between their societal beliefs and water consumption. Water being a key resource for life sustenance and lifestyle orientation is required by individuals regardless of price they have to pay for it as shown by the results indication the last criticality motives for consumption hold in this regard, meaning that the presence of motives would alter the consumption patterns in the if the motive induced subject is influenced by them.

The constructs partially influenced by the mediating factor included common neighbors, common industrialist and the quality of water which indicate the necessary presence of the mediating factor to a slight extent in order to have a proper bridged influence existing between them and actual consumption, directing to the fact that in some circumstances even the lack of motives would show a connection between them and water consumption. Contextualizing the result associated with water quality the consumption patterns would be seen as directly connected with a change in quality as most individuals are easily influenced by the apparent without showing much motive based inclination. Same goes for neighbors which are a major observable influence in the perceptive modification of the groups that surround them because of their easily observable consumption patterns. An individual may ignore basic consumption motives based on positive yet unexplored observation. Lastly in the context of industrial practices much though process has been reduced based on the wide spread of welfare awareness rendering the reduction in motive based water consumption in society while in some circumstances individual with heavily inclination towards information 
mining may develop a different set of motives mediating industrial practices and water consumption.

\section{Implications}

Further exploration may be done while incorporating the gaps in the partially connected concepts as well as the concepts prone to a mediation effect. Dimensions may have underlying segregation structures within observable latencies giving insight of the exogenous constructs explored in this study providing a dynamic context for future research. The issues pertaining to sustenance in response to the contamination spread can be addressed according to the behavioral depiction in the societal setting giving directives to the regulatory bodies (A. Ahmed \& Shafique, 2019). Owing to climatic forecasts, water protection can be proposed in a timely fashion providing greater opportunity for sustainable development alongside reducing barriers in progression. Special purpose endeavor channelization under the procedural generation of industry based outputs can be proclaimed as controllable with the applicable proprietary of data relative utility (Rasool et al., 2017). Control of waste in the agricultural setting can be routed effectively towards establishment in accordance with data pertinence and its collaborative utility with location relevance.

Expenditure in line with water treatment control is a major focus of regulatory management, addressable with societal transparency in the form of utility perceptions which would enable the governing management to better structure treatment monetization and procedures. Due to the problem's significance in Karachi locality based managers can benefit from the acquired knowledge of societal consumption pattern. Awareness of the considered and concerned localities would also be influenced by strategists based on the effective application of the data based regulatory framework. This would allow further to appropriate the preservation practices of water resources. Contemporarily, solutions regarding the excessive wastage of water resources alongside the lack of utility knowledge are required which can influence the drives of inhabitants, enabling managers to extract solutions for amending the current consumption patterns (A. Ahmed \& Shafique, 2019). Better propositions for treatment facilities can be presented despite the loss of resources. The current losses would only prove as productive track records for forecasting future regulations (Amin et al., 2019).

The behavioral patterns recognized in this study point out that societal dynamics observable from realistic perspectives and giving perception to influence based localities dominate water consumption patterns, some with motives and some without. Albeit, motives are essential drives for shifting any form of behavior, some influences are not motive based while some donot vary with or without the presence of motives. What is essential for users of the study is to extract which drives are influence only under observational conditions while which are under psychometric dominance. 


\section{Appendix}

Figure 1

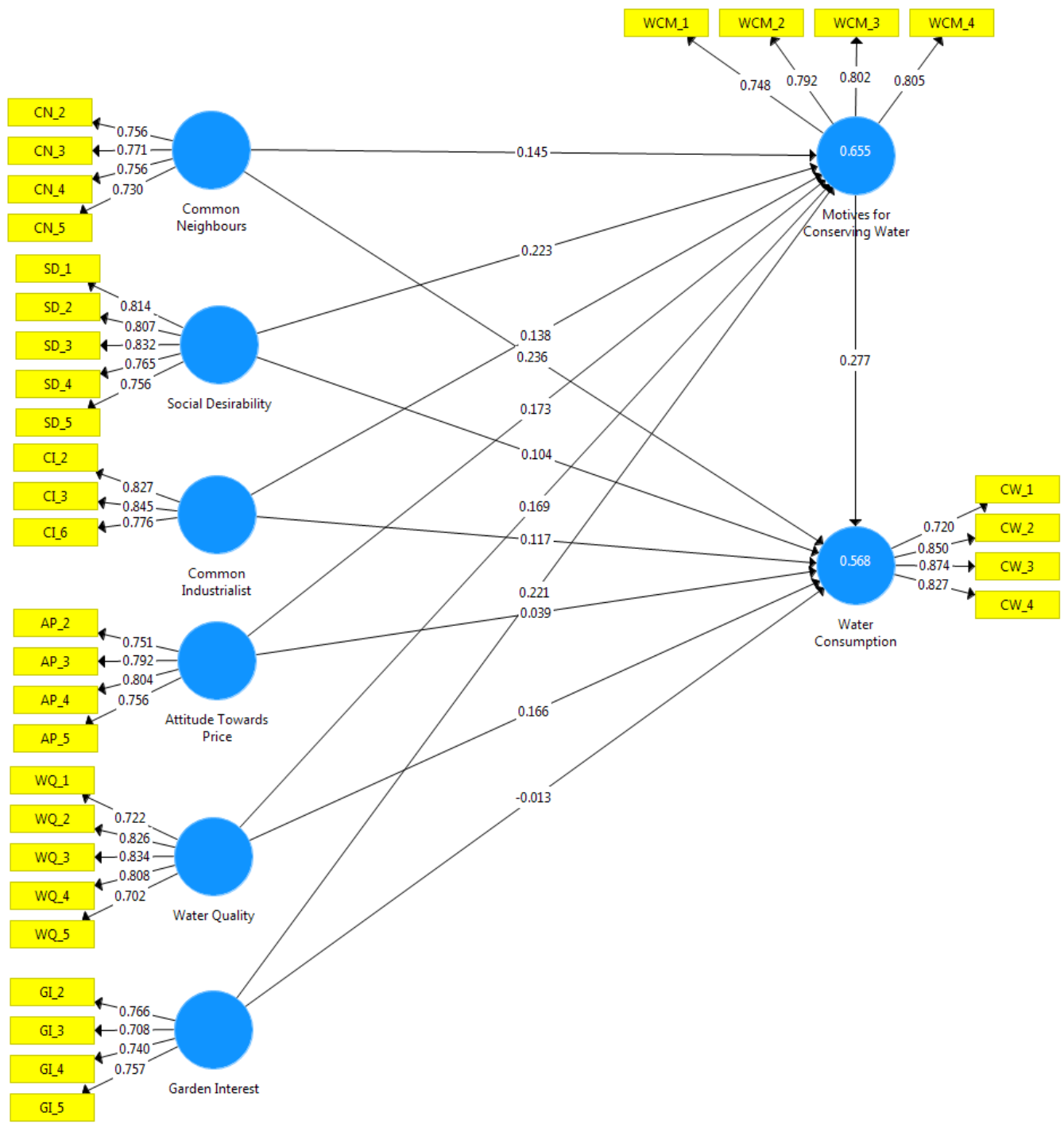


Figure 2

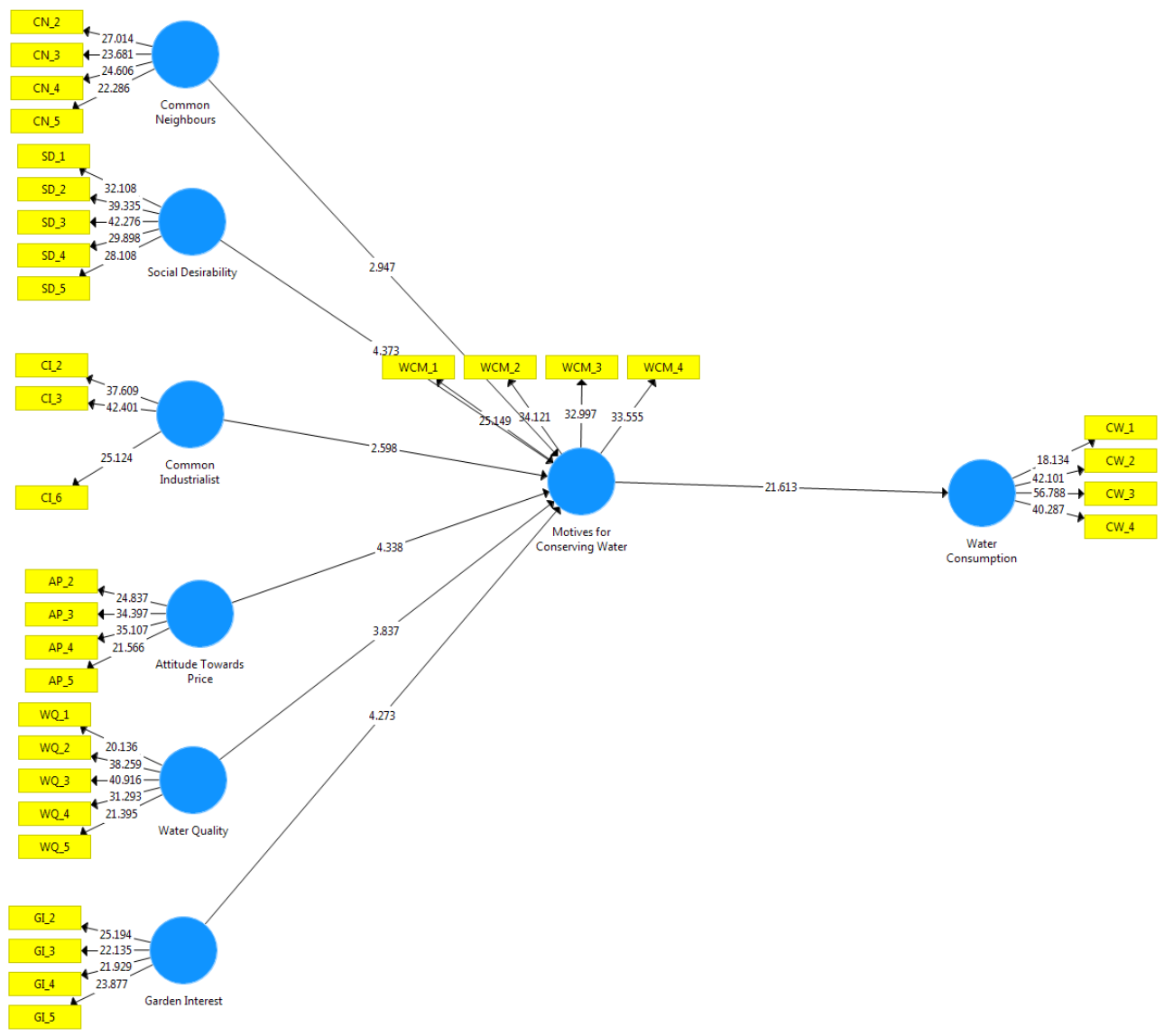


Figure 3

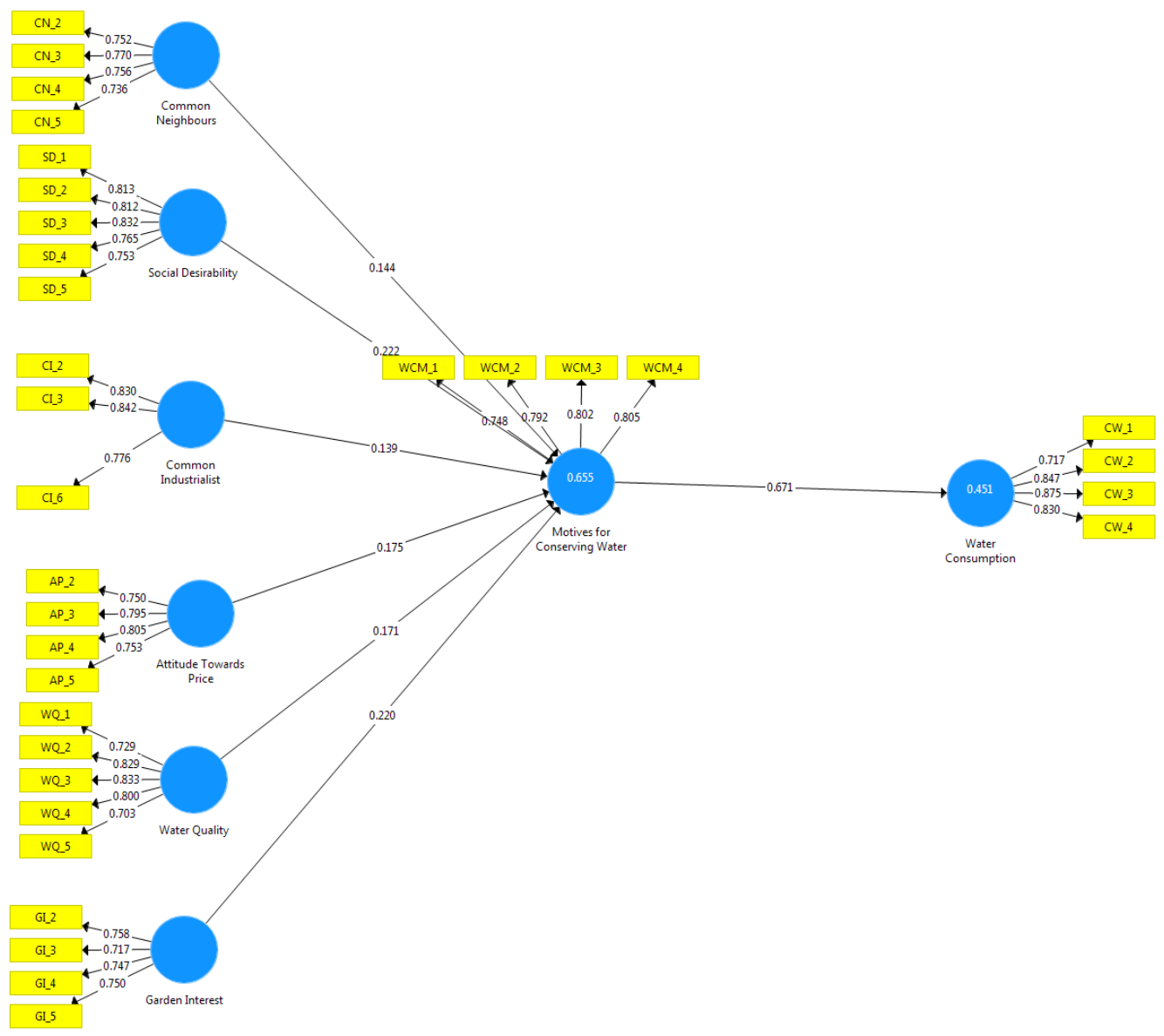


Figure 4

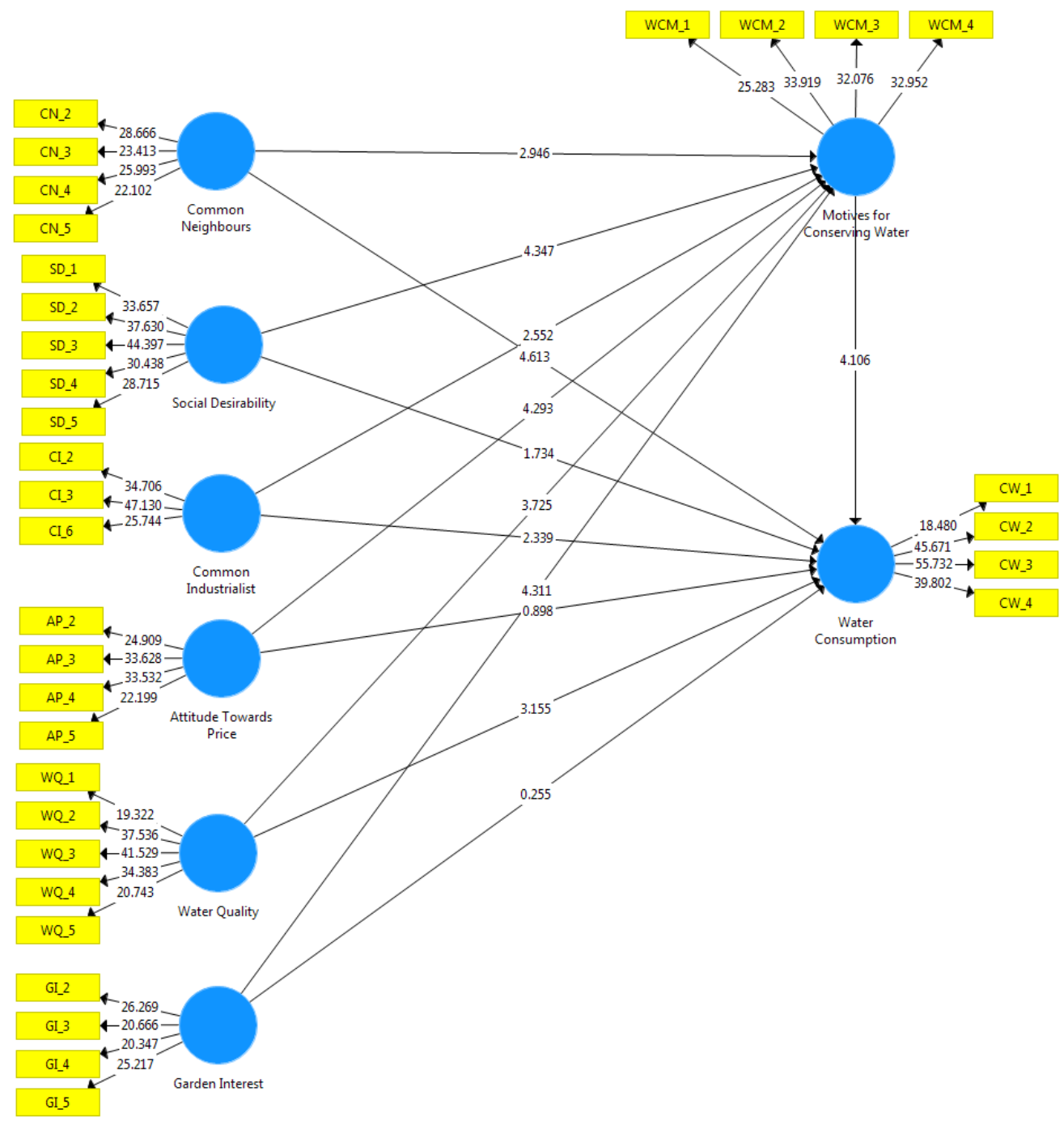




\section{References}

Ahmad, J., Khan, N. A., Shafiq, M. A., \& Khan, N. (2019). A low-cost wastewater treatment unit for reducing the usage of fresh water at car wash stations in Pakistan. Pakistan Journal of Scientific \& Industrial Research Series A: Physical Sciences, 62(1), 57-66.

Ahmed, A., \& Shafique, I. (2019). Perception of household in regards to water pollution: An empirical evidence from Pakistan. Environmental Science and Pollution Research, $26(9), 8543-8551$.

Ahmed, W., \& Omar, M. (2017). Drivers of supply chain transparency and its effects on performance measures in the automotive industry: Case of a developing country. International Journal of Services and Operations Management.

Amin, R., Zaidi, M. B., Bashir, S., Khanani, R., Nawaz, R., Ali, S., \& Khan, S. (2019). Microbial contamination levels in the drinking water and associated health risks in Karachi, Pakistan. Journal of Water, Sanitation and Hygiene for Development, 9(2), 319-328.

Balling Jr, R. C., Gober, P., \& Jones, N. (2008). Sensitivity of residential water consumption to variations in climate: An intraurban analysis of phoenix, arizona. Water Resources Research, $44(10)$.

Chang, H., Parandvash, G. H., \& Shandas, V. (2010). Spatial variations of single-family residential water consumption in Portland, Oregon. Urban Geography, 31(7), 953972.

Chin, W. W. (1998). Commentary: Issues and opinion on structural equation modeling. MIS Quarterly, 22(1), 7-16.

Corral-Verdugo, V., Frias-Armenta, M., Pérez-Urias, F., Orduña-Cabrera, V., \& EspinozaGallego, N. (2002). Residential water consumption, motivation for conserving water and the continuing tragedy of the commons. Environmental Management, 30(4), $527-535$.

Costa, V., \& Monteiro, S. (2016). Knowledge processes, absorptive capacity and innovation: A mediation analysis. Knowledge and Process Management, 23(3), 207-218.

Costanigro, M., Deselnicu, O., \& McFadden, D. T. (2016). Product differentiation via corporate social responsibility: Consumer priorities and the mediating role of food labels. Agriculture and Human Values, 33(3), 597-609.

de Miranda Coelho, J. A. P., Gouveia, V. V., de Souza, G. H. S., Milfont, T. L., \& Barros, B. N. R. (2016). Emotions toward water consumption: Conservation and wastage. Revista Latinoamericana de Psicología, 48(2), 117-126.

Dolnicar, S., Hurlimann, A., \& Grün, B. (2012). Water conservation behavior in Australia. Journal of Environmental Management, 105, 44-52.

Fan, L., Wang, F., Liu, G., Yang, X., \& Qin, W. (2014). Public perception of water consumption and its effects on water conservation behavior. Water, 6(6), 17711784

Fornell, C., \& Larcker, D. F. (1981). Evaluating structural equation models with unobservable variables and measurement error. Journal of Marketing Research, 18(1), $39-50$. 
Garrone, P., Grilli, L., \& Marzano, R. (2019). Price elasticity of water demand considering scarcity and attitudes. Utilities Policy, 59.

Gimenez, C., van der Vaart, T., \& van Donk, D. P. (2012). Supply chain integration and performance: The moderating effect of supply complexity. International Journal of Operations \& Production Management.

Hair, J. F., Ringle, C. M., \& Sarstedt, M. (2011). PLS-SEM: indeed a silver bullet. Journal of Marketing Theory and Practice, 19(2), 139-152.

Hair, J. F., Ringle, C. M., \& Sarstedt, M. (2013). Partial least squares structural equation modeling: Rigorous applications, better results and higher acceptance. Long Range Planning, 46(1-2), 1-12.

Hair, J. F., Sarstedt, M., Ringle, C. M., \& Mena, J. A. (2012). An assessment of the use of partial least squares structural equation modeling in marketing research. Journal of the Academy of Marketing Science, 40(3), 414-433.

Hair Jr, J. F., Hult, G. T. M., Ringle, C., \& Sarstedt, M. (2016). A primer on partial least squares structural equation modeling (PLS-SEM). Sage publications.

Hair Jr, J. F., Sarstedt, M., Hopkins, L., \& Kuppelwieser, V. G. (2014). Partial least squares structural equation modeling (PLS-SEM). European Business Review.

Jorgensen, B., Graymore, M., \& O'Toole, K. (2009). Household water use behavior: An integrated model. Journal of Environmental Management, 91(1), 227-236.

Lee, H. K., \& Fernando, Y. (2015). The antecedents and outcomes of the medical tourism supply chain. Tourism Management, 46, 148-157.

Leong, W. D., Teng, S. Y., How, B. S., Ngan, S. L., Lam, H. L., Tan, C. P., \& Ponnambalam, S. (2019). Adaptive analytical approach to lean and green operations. Journal of Cleaner Production, 235, 190-209.

Lindsay, J., \& Supski, S. (2017). Changing household water consumption practices after drought in three Australian cities. Geoforum, 84, 51-58.

Liu, J., Liu, Q., \& Yang, H. (2016). Assessing water scarcity by simultaneously considering environmental flow requirements, water quantity, and water quality. Ecological Indicators, 60, 434-441.

Mehmood, S. M., \& Najmi, A. (2017). Understanding the impact of service convenience on customer satisfaction in home delivery: Evidence from Pakistan. International Journal of Electronic Customer Relationship Management, 11(1), 23-43.

Morote, Á.-F., Hernández, M., \& Rico, A.-M. (2016). Causes of domestic water consumption trends in the city of alicante: Exploring the links between the housing bubble, the types of housing and the socio-economic factors. Water, 8(9), 374 .

$\mathrm{Mu}$, X., Whittington, D., \& Briscoe, J. (1990). Modeling village water demand behavior: A discrete choice approach. Water Resources Research, 26(4), 521-529.

Randolph, B., \& Troy, P. (2008). Attitudes to conservation and water consumption. environmental Science \& Policy, 11(5), 441-455.

Rasool, A., Xiao, T., Farooqi, A., Shafeeque, M., Liu, Y., Kamran, M. A., ... Eqani, S. A. M. A. S. (2017). Quality of tube well water intended for irrigation and human consumption with special emphasis on arsenic contamination at the area of Punjab, Pakistan. Environmental Geochemistry and Health, 39(4), 847-863. 
Sadr, S. M., Memon, F., Jain, A., Gulati, S., Duncan, A. P., Hussein, W., .. Butler, D. (2016). An analysis of domestic water consumption in Jaipur, India.

Shabbir, R., \& Ahmad, S. S. (2016). Water resource vulnerability assessment in Rawalpindi and Islamabad, Pakistan using analytic hierarchy process (AHP). Journal of King Saud University-Science, 28(4), 293-299.

Sønderlund, A., Smith, J., Hutton, C., \& Kapelan, Z. (2014). Using smart meters for household water consumption feedback: Knowns and unknowns. Procedia Engineering, 89, 990-997.

Syme, G. J., Shao, Q., Po, M., \& Campbell, E. (2004). Predicting and understanding home garden water use. Landscape and Urban Planning, 68(1), 121-128.

Yang, L., Yang, S.-H., Magiera, E., Froelich, W., Jach, T., \& Laspidou, C. (2017). Domestic water consumption monitoring and behaviour intervention by employing the internet of things technologies. Procedia Computer Science, 111, 367-375.

Zhu, Q., Sarkis, J., \& Lai, K.-h. (2012). Green supply chain management innovation diffusion and its relationship to organizational improvement: An ecological modernization perspective. Journal of Engineering and Technology Management, 29(1), 168-185.

Zivin, J. G., Neidell, M., \& Schlenker, W. (2011). Water quality violations and avoidance behavior: Evidence from bottled water consumption. American Economic Review, $101(3), 448-53$. 